\title{
Tracking the Global Distribution of Persistent Organic Pollutants Accounting for E-Waste Exports to Developing Regions
}

\author{
Knut Breivik, ${ }^{* \dagger,}$ James M. Armitage, ${ }^{*}$, Frank Wania, ${ }^{\S}$ Andrew J. Sweetman," and Kevin C. Jones" \\ ${ }^{\dagger}$ Norwegian Institute for Air Research, Box 100, NO-2027 Kjeller, Norway \\ ${ }^{\star}$ Department of Chemistry, University of Oslo, Box 1033, NO-0315 Oslo, Norway \\ ${ }^{\S}$ Department of Physical and Environmental Sciences, University of Toronto Scarborough, 1265 Military Trail, Toronto, Ontario \\ Canada M1C 1A4 \\ "Lancaster Environment Centre, Lancaster University, Lancaster LA1 4YQ U.K.
}

\section{Supporting Information}

ABSTRACT: Elevated concentrations of various industrial-use Persistent Organic Pollutants (POPs), such as polychlorinated biphenyls (PCBs), have been reported in some developing areas in subtropical and tropical regions known to be destinations of e-waste. We used a recent inventory of the global generation and exports of e-waste to develop various global scale emission scenarios for industrial-use organic contaminants (IUOCs). For representative IUOCs (RIUOCs), only hypothetical emissions via passive volatilization from e-waste were considered whereas for PCBs, historical emissions throughout the chemical life-cycle (i.e., manufacturing, use, disposal) were included. The environmental transport and fate of RIUOCs and PCBs were then simulated using the BETR Global 2.0 model. Export of e-waste is expected to increase and sustain global emissions beyond the baseline scenario, which assumes no export. A comparison between model predictions and observations for PCBs in selected recipient regions generally suggests a better agreement when exports are accounted for. This study may be the first to integrate the global transport of IUOCs in waste with their long-range transport in air and water. The results call for integrated chemical management strategies on a global scale.

\section{INTRODUCTION}

There are many ways in which harmful chemicals may travel around the globe and have adverse effects, far away from the locations of their production and initial use. Well-known examples are Persistent Organic Pollutants (POPs) which are characterized by their ability to undergo long-range transport (LRT) to remote areas. ${ }^{1,2}$ Considerable research efforts have therefore been invested over the last decades to monitor the occurrence and trends of POPs in the Arctic ${ }^{3,4}$ and to study global source-receptor relationships using various modeling approaches. $^{5-8}$ About a decade ago, the Stockholm Convention (SC) on POPs entered into force to protect environment and human health from the harmful effects of substances that are explicitly recognized as also being prone to LRT. Air is chosen as a core monitoring medium in order to evaluate the effectiveness of the SC through the detection of possibly declining temporal trends as well as to provide information on the regional and global environmental transport of POPs. ${ }^{9}$ The enrichment of POPs in cold regions is partly attributed to enhanced atmospheric deposition at lower temperatures, that is, cold trapping. ${ }^{10}$ As volatilization of semivolatile POPs from surface reservoirs (e.g., contaminated materials, soils, vegetation) is a function of temperature, ${ }^{11,12}$ an elevated potential for atmospheric emissions could be expected in tropical areas, all else being equal.
While initially the focus has been predominantly on atmospheric LRT, there are other modes of LRT by which POPs could move around the globe (e.g., LRT in ocean currents, as is the case for perfluoroalkylated acids). ${ }^{13}$ An intriguing example of "non-environmental" LRT is the often illicit export of e-waste (discarded electrical and electronic equipment) toward developing areas in subtropical and tropical regions. $^{14-16}$ E-waste may contain both legacy POPs like polychlorinated biphenyls (PCBs), polybrominated diphenyl ethers (PBDEs) as well as other semivolatile organic contaminants (e.g., other halogenated flame retardants), collectively referred to as industrial-use organic contaminants (IUOCs) herein. However, export of e-waste also represents LRT of resources as it contains, for example, valuable metals and spare parts which may be recovered and generate income in developing regions. Allegedly, the main driving force of the global e-waste trade is the profit which can be obtained through exports and recovery of such resources in developing regions. ${ }^{17}$ Over the past decade, numerous monitoring studies have documented elevated levels of various IUOCs in the

Received: August 31, 2015

Revised: December 15, 2015

Accepted: December 15, 2015 
atmosphere and thus emissions near known or suspected ewaste receiving and processing sites in subtropical and tropical areas. $^{18-25}$ For example, a recent field study at a major e-waste site in southern China reported major primary emissions due to evaporation of $\mathrm{PCBs}$ with possible additional emissions from recycling processes such as shredding and burning. ${ }^{26}$ Yet, LRT of IUOCs present in waste products remains largely ignored in studies of global emissions, transport and distribution of such chemicals. $^{27}$ This calls for (i) methodologies to assess the impact of a potential shift in global sources and source regions of IUOCs toward developing regions at lower latitudes as well as (ii) methodologies to integrate LRT by environmental as well as non-environmental modes.

As there are (i) major uncertainties associated with the global flows of individual e-waste categories and their constituents, as well as (ii) uncertainties in the magnitude of emissions from informal recycling and disposal of e-waste in developing regions, a tiered approach has been adopted. Our main research objective was to explore the potential implications for emissions, transport and exposures for IUOCs, attributed to a shift in source regions of e-waste toward tropical regions. For the first case study, global emission scenarios are developed for representative IUOCs (RIUOCs) in a world with and without exports of e-waste ${ }^{28}$ where it is assumed that emissions occur only via passive volatilization from disposal/recycling sites. These hypothetical emission scenarios are then used as input to an existing global model to simulate the distribution of RIUOCs in the environment to assess implications for fate and transport. ${ }^{29}$ Recognizing that passive volatilization is not the only source of emissions of IUOCs, the second case study more realistically explores the implications of e-waste exports for global emissions of selected PCBs. PCBs were selected for this case study because a global emission inventory already exists $^{30}$ and monitoring data have been reported in source, remote, and e-waste receiving locations. ${ }^{21,31}$ The existing global historical emission inventory ${ }^{30}$ was updated to account for scenarios including exports of wastes, followed by time variant fate and transport calculations for the period 1930-2030. The purpose of this case study is to assess the potential implications of e-waste related emissions in developing regions, which simultaneously account for historical emissions and long-range transport of selected PCBs as well as emissions during other stages of the chemical life-cycle.

\section{MATERIALS AND METHODS}

2.1. Global Emission Scenarios. 2.1.1. Hypothetical Emission Scenarios for Industrial-Use Organic Contaminants from E-Waste (Passive Volatilization Only). For this case study, we constructed two generic emission scenarios, representing a world with and without the global trade of ewaste. Specifically, we set out to estimate how the propensity of emission from e-waste attributed to passive volatilization of RIUOCs alone could be expected to vary across the globe in a world with and without e-waste exports and imports. The motivation for these hypothetical scenarios was 3-fold, namely to (i) assess possible implications for transport and exposures attributed to e-waste exports in isolation, (ii) restrict the analysis to a set of transparent assumptions with a mechanistic basis, and (iii) develop generic scenarios to compare and contrast findings for PCBs and beyond (2.1.2).

The generic emission scenarios for RIUOCs were constructed by assuming that the emissions are a function of (i) the relative amount of e-waste assumed present in a given model zone in $2005,{ }^{28}$ which is either $M_{\mathrm{GEN}}$ in a world without exports/import of e-waste or $M_{\mathrm{NET}}=M_{\mathrm{GEN}}+M_{\mathrm{IMP}}-M_{\mathrm{EXP}}$ in a world with such e-waste flows, and (ii) the relative emission strength (based on passive volatilization). For the emission scenarios reported here, the amount of e-waste present in a given model zone excluded the amount associated with large household appliances (LHA), which account for approximately $50 \%$ of the total amount collected in the European Union in $2005 .^{28}$ This proportion was assumed to be representative for all model zones (i.e., $M_{\mathrm{GEN}}$ was divided by two in all zones). This assumption is based on the expectation that (i) relatively small amounts of IUOCs are present in these products compared to other e-waste categories (e.g., IT and telecommunications equipment) and that (ii) LHA make up a small proportion of the bulk of e-waste exports (i.e., exports are predominantly smaller items like computers and other electronics). The net effect of excluding LHA is to magnify the relative importance of e-waste exports in determining the overall emissions in each zone compared to scenarios where LHA are included in the e-waste inventories.

The construction of the emission scenarios required the selection of a reference location and temperature. For the purposes of this exercise, Zone 61 (Central Europe) of the BETR Global model ${ }^{29}$ (Supporting Information, Figure S1) was the reference zone and the average temperature in the warmest month in this zone (July, 289.3 K) was the reference temperature. A passive volatilization emission factor (PVEF) for Zone 61 in July was defined to equal one. PVEFs in every other month and zone were then calculated using the following expression: ${ }^{12}$

$$
\frac{\mathrm{PVEF}_{2}}{\mathrm{PVEF}_{1}}=\exp \left[\frac{\Delta U_{A}}{R} \cdot\left(\frac{1}{T_{1}}-\frac{1}{T_{2}}\right)\right]
$$

where $\mathrm{PVEF}_{2}$ is the PVEF in the zone of interest in a given month, $\mathrm{PVEF}_{1}$ is the PVEF in Zone 61 in July $\left(\mathrm{PVEF}_{1}=1\right)$, $\Delta U_{\mathrm{A}}$ is the internal energy of vaporization $(\mathrm{J} / \mathrm{mol}), R$ is the ideal gas law constant, $T_{1}$ is the average temperature in Zone 61 in July $\left(T_{1}=289.3 \mathrm{~K}\right)$ and $T_{2}$ is the average temperature in the zone and month of interest. The amount of e-waste present in a given zone was multiplied by the monthly PVEFs to yield an emission, the 12 monthly emissions were summed and the annual emission flux was then normalized to that calculated for Zone 61. Accordingly, emissions in Zone 61 in the $M_{\mathrm{GEN}}$ scenario without e-waste trade are by definition equal to one and the amount emitted in other zones are scaled to this value. For example, Zone 79 (Eastern U.S.) contains approximately the same amount of e-waste as Zone 61 under the $M_{\mathrm{GEN}}$ scenario; however, because of the warmer temperatures throughout the year, the normalized emissions via passive volatilization are approximately 2.0-4.5-fold higher (for $\Delta U_{\mathrm{A}}$ ranging from 78.4 to $145 \mathrm{~kJ} / \mathrm{mol}$ ). Please note that in the $M_{\mathrm{NET}}$ scenario with global e-waste trade, the emissions were also normalized to those for Zone 61 in the $M_{\mathrm{GEN}}$ scenario. Based on this procedure, emissions in Zone 61 under the $M_{\mathrm{NET}}$ scenario are approximately half of the emissions in the $M_{\mathrm{GEN}}$ scenario, because of the export of e-waste from central Europe. Normalized emissions for the two scenarios in a few other key model zones are summarized in the SI Table S1.

We emphasize the hypothetical character of the generic emission scenarios as they ignore (i) emissions of RIUOCs occurring during other phases of the chemical life-cycle (e.g., production, use) and (ii) differences in the potential for 
emissions due to specific recycling and disposal practices. Emissions occurring for reasons other than passive volatilization are only considered in the global PCB emission scenarios described below. Also note that passive volatilization from waste products can only occur for certain chemical use patterns, such as RIUOCs present as additives, but is not applicable to chemicals present as a "reactive" (e.g., tetrabromobisphenol A covalently bound in epoxy resins).

2.1.2. Updated Global Emission Scenarios for PCBs Accounting for Export of E-Waste. For the second case study, estimated global historical emission scenarios for selected PCB congeners that account for the transboundary movement of e-wastes toward developing regions were developed by building upon global historical emission scenarios previously derived with a dynamic mass balance/flow approach. ${ }^{30,32-34}$ Emissions throughout the chemical life-cycle (i.e., manufacturing, use, disposal) via multiple pathways are considered. A condensed summary of this methodology, relevant for the update, is provided in the Supporting Information. In this study, three emission scenarios are discussed. The "baseline" scenario (no export) is included to facilitate a direct comparison with two scenarios that account for e-waste exports ("default" and "high").

In the parametrization of the original emission mass balance model, control measures to reduce emissions of PCBs by formal collection of electrical equipment containing PCBs in closed systems (capacitors and transformers) was gradually implemented from the 1980 s onward, reaching up to $50 \%$ by the year $2000 .^{33}$ It was further assumed that any such electrical equipment collected for recycling was subject to complete destruction at designated facilities. ${ }^{30,33}$ The revised PCB emission mass balance model (shown in Figure 1) assumes

\begin{tabular}{|c|c|c|}
\hline Continuous source & Flow & ค Degradation \\
\hline Instantaneous source & Emissions & ---- Transboundary flow and fate \\
\hline
\end{tabular}

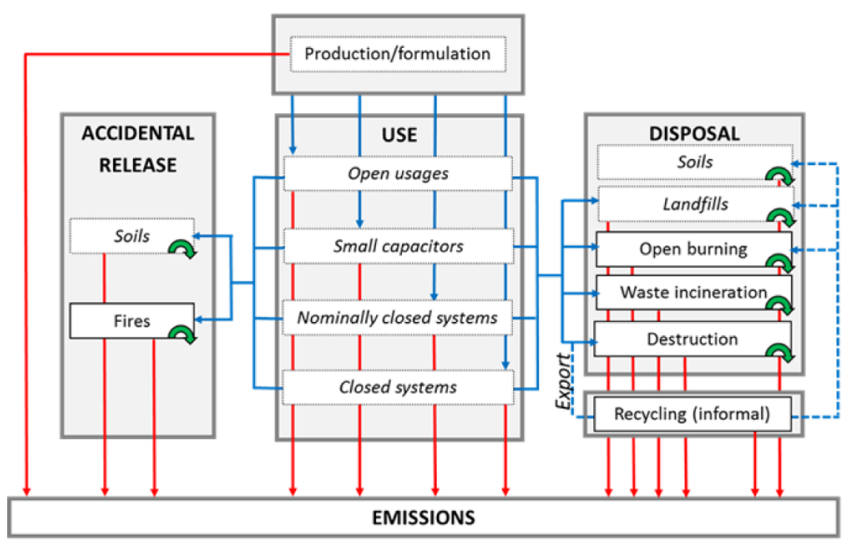

Figure 1. Revised dynamic mass balance model applied to develop emission scenarios for selected PCBs. New processes accounting for transboundary flow and fate of e-waste, attributed to export from OECD to selected non-OECD countries are indicated by stipulated lines and arrows.

that a fraction of the e-waste collected in OECD countries for recycling ${ }^{33}$ is instead diverted for export to developing regions. For the two new scenarios that account for e-waste exports, that fraction is set to $23 \%(33.5 \%)$. The import in seven selected non-OECD countries from the OECD was distributed as follows: ${ }^{28}$ China: $71.6 \%$ (72.2\%), India: 9.0\% (11.6\%), Nigeria:
16.1\% (13.9\%), Ghana: $3.0 \%$ (2.0\%), Cote d'Ivore: $0.24 \%$ (0.16\%), Benin: $0.10 \%(0.07 \%)$, and Liberia: $0.007 \%$ (0.005\%).

Once in the seven importing countries, we assume the ewaste to become subject to informal recycling (e.g., manual dismantling/shredding). As PCBs were extensively used in closed electrical systems with limited potential for emissions during the use stage, informal processing inevitably increases the risk for environmental releases, considered here as a transition from closed to open usage. After dismantling, the ewaste is assumed either to be (i) disposed in landfills, (ii) dumped onto soils, ${ }^{35}$ or (iii) subject to open burning. A notable difference between these three disposal options is that emissions from soils and landfills are treated as continuous sources, modeled as dynamic stocks, whereas open burning is an instantaneous source. ${ }^{33}$ They also differ significantly in terms of the potential for emissions, with the latter having a clearly higher emission factor. ${ }^{33}$ For this study, informal recycling and dismantling were assigned the same emission factors as was used for open usage in the original study, ${ }^{33}$ due to lack of empirically determined emission factors applicable to informal processing in developing regions. In the "default" scenario 5\% of the disposed e-waste is subject to open burning, with the remaining e-waste equally divided between soils and landfills. In the "high" scenario, representing a reasonable worst-case, that fraction is increased to $20 \%$.

2.1.3. Spatial Distribution of Emissions. The global emission inventories for all chemicals (with and without considering exports) were spatially distributed on a $1^{\circ} \times 1^{\circ}$ latitude/longitude basis, using population density as a surrogate to allocate emissions within each country. We caution that this represents a first approximation which may not be appropriate for informal recycling in poor communities in countries where wealth and population do not correlate well. However, in the specific case of China, the coordinates of the three major ewaste areas were explicitly accounted for in the spatial distribution of both RIUOC and PCB imports: Guiyu 27.4\% (15.3-27.8\%); Qingyuan 20.3\% (19.5-23.6\%); Taizhou 34.3\% (30.6-47.1\%); import to rest of China: $18 \% .^{28}$ For the global transport and fate modeling (see below), emissions with a $1^{\circ} \mathrm{X}$ $1^{\circ}$ resolution were aggregated to match the spatial resolution of the model $\left(15^{\circ} \times 15^{\circ}\right)$.

2.2. Global Transport and Fate Modeling. 2.2.1. BETRGlobal 2.0. All simulations were carried out using the geographically explicit multimedia contaminant fate model BETR-Global 2.0. ${ }^{29}$ The global environment is modeled on a $15^{\circ} \times 15^{\circ}$ grid as a set of 288 multimedia regions connected by flows of air and water. The model has been evaluated and applied for various organic contaminants, including PCBs. ${ }^{12,36,37}$ For this work, the only input data altered from the original parametrization ${ }^{29}$ were the physical-chemical property values (2.2.2) and emission scenarios. For simulations using the RIUOC emission scenarios (2.1.1), the model was operated in steady-state mode, whereas dynamic simulations (1930-2030) were utilized for the PCB emission scenarios (2.1.2).

2.2.2. Physical-Chemical Property Values and Environmental Half-Lives. Four chemicals, PCB 28, PCB 153, BDE 47 and BDE 209, were selected to be the representative IUOCs. Physical-chemical properties for the RIUOCs and five other PCBs (PCB, 52, 101, 118, 138, and 180) are summarized in the SI (Tables S2 and S3). The property values for all chemicals are those from the default property database ${ }^{38-41}$ included with the 

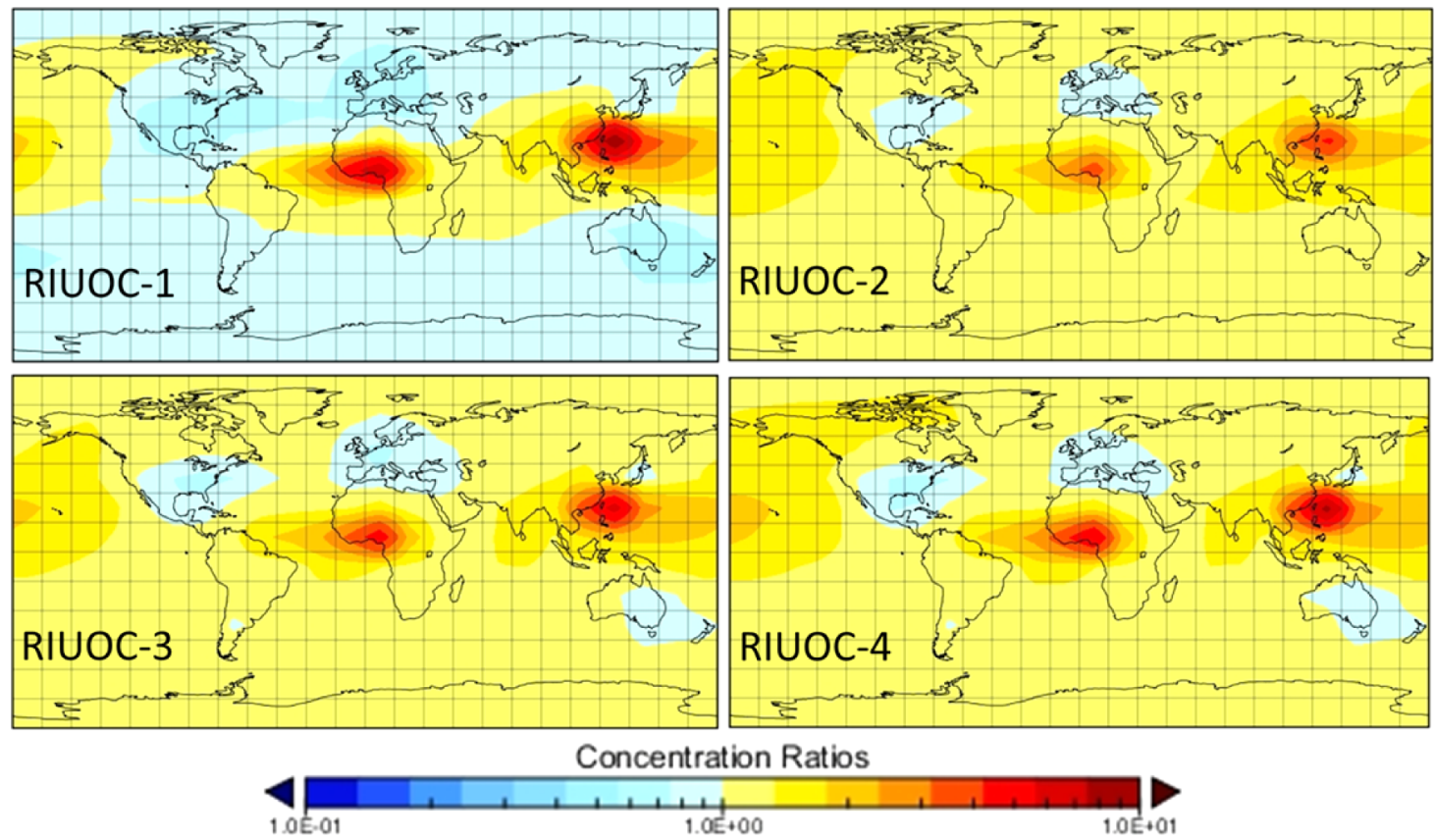

Figure 2. Ratios of steady-state concentrations calculated with BETR Global 2.0 for the lower air compartments using scenarios with (enumerator) or without (denominator) the export of e-waste from OECD countries to developing countries for four representative industrial-use organic contaminants (RIUOC-1-4). The differences in steady-state concentration ratios illustrated in Figure 2 for RIUOC-1 vs RIUOC-2-4 mainly reflect differences in long-range transport potential (e.g., susceptibility to $\mathrm{OH}$ radical reactions in the atmosphere).

BETR Global model ${ }^{29}$ (https://sites.google.com/site/ betrglobal/).

\section{RESULTS AND DISCUSSION}

\subsection{Emissions, Transport and Exposure of RIUOCs} (Passive Volatilization Only). Accounting for e-waste exports $\left(M_{\mathrm{NET}}\right)$ causes total global emissions of the four RIUOCs to increase by between $31 \%$ (RIUOC-1) and $47 \%$ (RIUOC-4), relative to the baseline scenario with no export $\left(M_{\mathrm{GEN}}\right)$. The difference for individual RIUOCs reflects differences in the internal energy of vaporization, being higher for the less volatile RIUOC-4 $(145 \mathrm{~kJ} / \mathrm{mol})$ compared to the more volatile RIUOC-1 $(74.8 \mathrm{~kJ} / \mathrm{mol})$. The total emissions in e-waste receiving zones increase more dramatically. For example, accounting for e-waste exports $\left(M_{\mathrm{NET}}\right)$ results in 7-9-fold increases in emissions in West Africa (see Figure S1; Zones 132, 133) and 5-40-fold increases in China (see Figure S1; Zones 116, 117). The 40-fold increase in China (Zone 117) occurs because an e-waste receiving site is located in this zone (Taizhou). ${ }^{27}$ As this zone otherwise generates very little e-waste due to the small proportion of the zone covered by land, emissions related to e-waste import have a large influence. Emissions via passive volatilization in Zones 116 and 117 are similar in absolute terms in the e-waste exports $\left(M_{\mathrm{NET}}\right)$ scenarios however.

Model outputs accounting for e-waste exports $\left(M_{\mathrm{NET}}\right)$ were compared to the baseline scenario $\left(M_{\mathrm{GEN}}\right)$ by calculating the ratios of the steady-state concentrations in each compartment in each model zone (e.g., concentration ratio in lower air compartment $\left.=C_{\text {air }}^{M \text { net }} / C_{\text {air }}^{M \text { gen }}\right)$. Because the steady-state concentration ratios in lower air are representative of surface compartments as well, only these concentration ratios are discussed here. The resulting steady-state concentration ratios in lower air clearly become elevated in recipient regions in West Africa and Southeast Asia (Figure 2). In contrast, concen- trations in exporting OECD regions are only marginally reduced when export is considered. Again, there are notable differences in concentration ratios for the four RIUOCs. Because RIUOC-1 is less persistent, the elevated concentrations are more confined to regions closer to recipient regions, whereas the more persistent RIUOCs with a longer atmospheric half-life are distributed further on a global scale. In any case, the total global environmental inventory (all compartments) increases for all RIUOCs, the increase ranging from $5 \%$ (RIUOC-1) up to $38 \%$ (RIUOC-4) in spite of the predicted decrease in the overall persistence in the global environment ( $-6 \%$ for RIUOC-4 up to $-20 \%$ for RIUOC- 1 ). The latter effect is attributed to increased reactivity at lower latitudes, but this is countered by the increased potential for emissions when export is considered. Overall, the steady-state results indicate that the regions receiving e-waste are subject to elevated concentrations by a factor of approximately 5 to 10 on a regional scale, dependent on the RIUOC in question. The potential reductions in concentrations in exporting regions are much smaller in comparison (less than a factor of 2 for RIUOC-1, 10-30\% for RIUOC-2-4). As the model predictions for RIUOCs involve hypothetical emission scenarios (i.e., passive volatilization only), they cannot be evaluated directly against measurements.

3.2. Emissions, Transport and Exposures of PCBs (Realistic Scenarios). 3.2.1. Global PCB Emission Scenarios. A comparison of global annual production, total annual new usage in electrical equipment (EE) within the OECD, stock in use in electrical equipment within the OECD is shown in Figure 3A. In Figure 3B, we have plotted the estimated annual export of $\Sigma_{22} \mathrm{PCBs}$ from OECD to selected non-OECD countries for the three e-waste export scenarios (high, default, low), compared with previous estimates for the global annual production, annual new use in electrical equipment (EE) as well as amounts in EE (for OECD only) at any time during the 

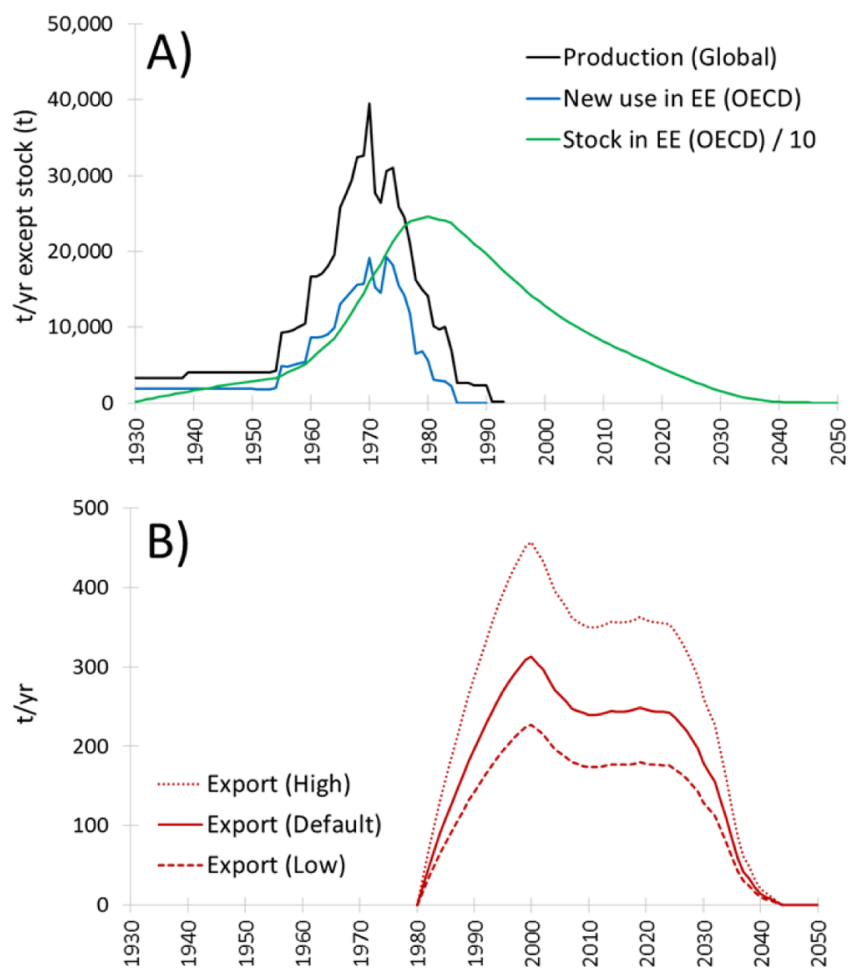

Figure 3. Comparison of global annual production, total annual new usage in electrical equipment (EE) within the OECD, stock in use in electrical equipment within the OECD (A) and three scenarios for export of PCBs from the OECD (B) from 1930 to 2050. All data are given for $\sum_{22} \mathrm{PCBs}$ and have the unit of $t / \mathrm{yr}$, except amount in electrical equipment which is given in $t$ divided by 10 .

presented time period (Figure 3A). ${ }^{30}$ Overall, the use of PCBs in EE within the OECD accounted for $\sim 69 \%$ of the historical usage or about half the total historical production of PCBs. The total amount in EE within the OECD is estimated to have peaked in the late 1970s to decline steadily thereafter (Figure 3A). The temporal pattern predicted for individual export scenarios share some common features (Figure 3B). From 1980 until 2000, there is a steady and sharp increase, reflecting the original assumption of an increase in the collection of EE for recycling and thus now also exports. For the period from 2000 up to 2010, there is a slight decline in exports, reflecting declining amounts in EE within the OECD, followed by a plateau for the next two decades and a steep decline thereafter. The latter feature is less intuitive, but is a reflection/artifact of the assumption of enhanced wear-out rates of EE toward the end of their use-life expectancies, ${ }^{30}$ which in turn leads to export of PCBs being sustained beyond what could be anticipated judging from amounts in use alone and with a swift decline thereafter (Figure 3B). The underlying scenario discussed assumes a use-life expectancy of small capacitors and closed systems (e.g., large capacitors and transformers) to be 15 and 30 years, respectively. ${ }^{30,33}$ As it is furthermore assumed that any $\mathrm{EE}$ is malfunctioning when twice the use-life expectancy has passed, ${ }^{30}$ this implies that usage of PCBs within EE of the OCED is predicted to cease 60 years after the last batch of closed systems were introduced on the market (Figure 3A). The overall results in terms of temporal emission trends are illustrated for PCB-153 in Figure 4.

3.2.2. Global Transport and Exposures of PCBs. Globalscale fate modeling studies of PCBs using the historic emission

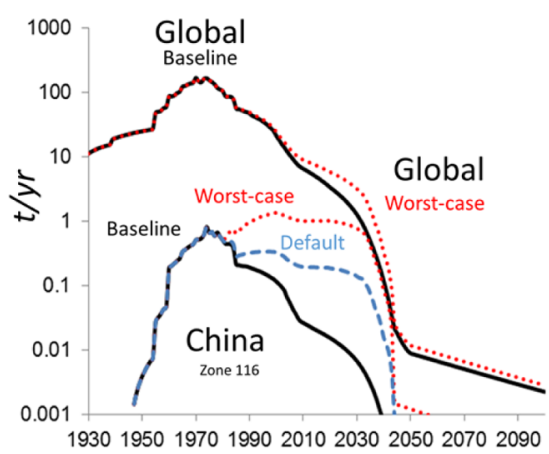

Figure 4. Aggregated emission estimates for PCB 153 in $t / y r$ for different emission scenarios over the period 1930-2100 (see also Figure S2).

inventories developed previously have documented the satisfactory agreement between reported and predicted atmospheric concentrations of PCBs in temperate and northern latitudes (e.g., EMEP monitoring sites). ${ }^{12,36,42}$ As emissions in major source regions where PCBs were more extensively produced and used in the past are similar in magnitude under the revised emission inventories (see above), no detailed evaluation for these regions was conducted here.

A comparison of monitoring data $\left(\sum_{7} \mathrm{PCBs}, \mathrm{pg} / \mathrm{m}^{3}\right)$ for China $^{31}$ (Zones 92, 93, 116) and West Africa ${ }^{21}$ (Zones 132, 133) and model output (high e-waste emission scenario) is presented in Figure 5. Agreement between the reported

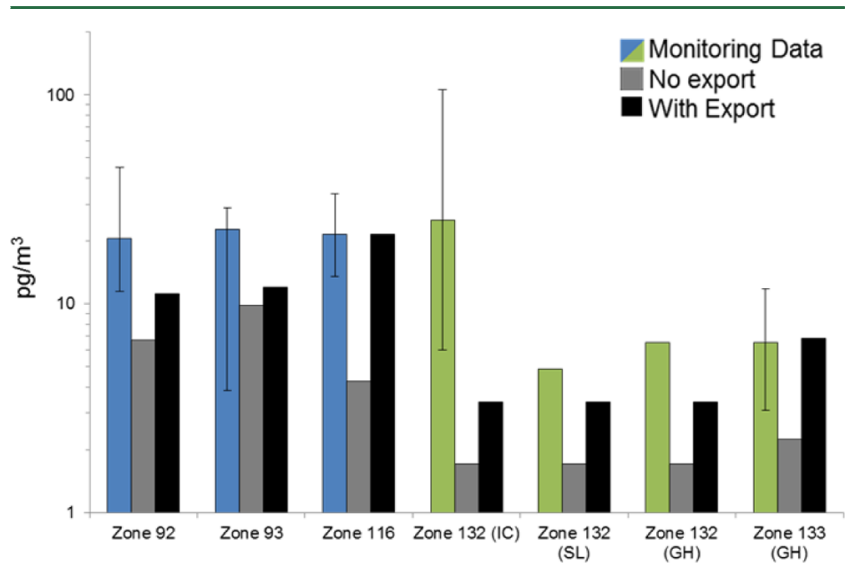

Figure 5. Reported geometric mean concentrations (with range from min to max.) of $\sum_{7} \mathrm{PCBs}$ in air $\left(\mathrm{pg} / \mathrm{m}^{3}\right)$ in (i) Fall 2004 derived from passive air samplers (PUF) deployed in rural areas of China located in Zones 92, 93, and 116 (blue bars) and (ii) Spring/Summer 2008 derived from passive air samplers (PUF) deployed in West African countries in Zone 132 and 133 (green bars) in comparison to model output for the 'No Export (baseline)' and 'With export (high)' scenarios (gray and black bars). IC $=$ Ivory Coast; $S L=$ Sierra Leone, $\mathrm{GH}=$ Ghana

concentrations of PCBs and model output is always improved under the revised emission scenarios considering transport of ewaste. The largest discrepancy between model output and monitoring data is observed for the Ivory Coast (Zone 132, IC). This discrepancy may indicate underestimation of emissions but may also reflect issues related to the relatively coarse spatial resolution of the BETR Global model. Predicted concentrations generated by the model are averages for the entire $15^{\circ} \times 15^{\circ}$ zone and hence not representative of monitoring data collected in close proximity to point sources 
(e.g., urban regions, landfills, e-waste processing sites). Nevertheless, the model evaluation supports the hypothesis regarding the potential importance of e-waste transport for POP emissions. Further investigation is warranted. Long-term model simulations conducted at a higher spatial resolution would be valuable, particularly for more rigorously assessing the plausibility of the three revised emission scenarios (baseline, default, high).

3.3. Implications for Research Needs and Control Strategies. 3.3.1. Emissions. The results for the RIUOCs reinforces that emissions of semivolatile organic contaminants are likely to increase because of transfer of organic chemicals to warmer regions. In order to minimize the potential for atmospheric emissions of semivolatile RIUOCs, export to subtropical and tropical regions is therefore not warranted in the context of global emission reduction strategies. We also caution that the hypothetical emission scenarios for RIUOCs presented in section 3.1 may be considered conservative because differences between formal and informal recycling and disposal practices are not accounted for. Accounting for such difference is likely to exacerbate the changes in emissions depicted in these generic scenarios, which for RIUOCs assume passive volatilization alone. The emission scenarios for PCBs (section 3.2) highlights that an accompanying transition from formal to informal recycling and disposal may exacerbate the changes in emissions which is particularly strong if EE containing these chemical becomes subject to open burning.

Taken together, warmer temperatures and informal recycling in developing regions are likely to lead to enhanced global emissions compared to the baseline scenario (no export). Yet, the magnitude of these effects remain uncertain because of (i) uncertainties in source-receptor relationships for e-waste and their possible change in time, which in turn is mainly caused by the lack of reliable activity data caused by the illicit nature of such operations, ${ }^{28}$ and (ii) uncertainties in estimated emissions of PCBs, subject to informal recycling and disposal because of lack of reliable activity data and emission factors. Further research efforts to develop more reliable emission inventories for IUOCs from e-waste areas are therefore critically needed.

3.3.2. Transport, Fate and Exposures. Emissions of PCBs related to e-waste transport to developing regions are predicted to have only a modest impact on the temporal trends of atmospheric concentrations in most historic source regions (e.g., Central Europe) (Figure 6) and in the Arctic (data not shown). In other words, the general decline in ambient PCB concentrations over the past few decades is expected to continue in these locations, following from the continued decline in primary emissions. While the e-waste transport related emissions of $\mathrm{PCBs}$ become relatively more important in the future (e.g., remaining global inventory of $\mathrm{PCBs} 50 \%$ higher in 2030 compared to no e-waste scenarios), the absolute levels in the environment and hence exposure are still well below contemporary and peak historic levels in most locations.

However, as illustrated in the Supplementary Data (Figure S4), the temporal trends of atmospheric concentrations in developing regions receiving and processing e-waste at the regional scale can be strongly influenced. Note that at the local scale (e.g., sites in close proximity to informal e-waste processing sites), temporal trends in ambient PCB concentrations could even diverge from the regional and global-scale patterns (i.e., show increasing concentrations during the last decades, rather than stable or decreasing levels). ${ }^{43,44}$ With respect to human and ecological exposure to $\mathrm{PCBs}$, the priority

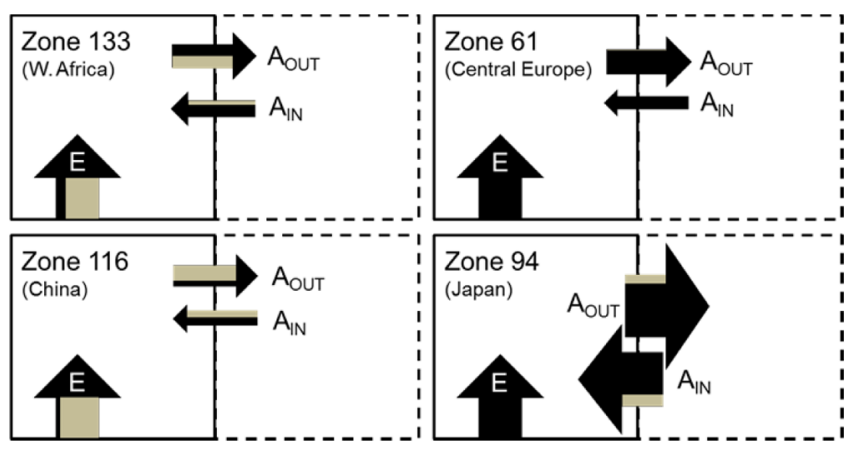

Figure 6. Comparison of atmospheric emissions $(E)$, advective inflow $\left(A_{\mathrm{IN}}\right)$ and advective outflow $\left(A_{\mathrm{OUT}}\right)$ for $\sum_{7} \mathrm{PCBs}$ for selected model zones in 2005, reflecting the high emission scenario with e-waste export (see also Figure S3) against the baseline scenario. The width of each arrow scales to the emission flux within each zone (harmonized across zones), and the contributions attributed to flows of e-waste alone are highlighted in light brown. The high emission scenario for Zones 133, 61, 116, and 94 as harmonized across zones were 3.5, 13.3, 8.7 , and 1.7 t $\sum_{7} \mathrm{PCBs} / \mathrm{yr}$ in 2005 , respectively.

for future monitoring and modeling efforts should therefore be at the local to regional scale. A nested approach (e.g., local, regional, continental scale) where known e-waste receiving sites are modeled at greater spatial resolution compared to other locations could be implemented. Such efforts still require an improved understanding of e-waste flows at regional to global scale however as well as emission factors for the recycling/ processing methods employed at different locations.

3.3.3. Control Strategies. This study likely marks the first attempt to numerically integrate LRT by both environmental and non-environmental modes in the scope of global chemical fate. Only an integrated approach, seeking a quantitative understanding of how these chemicals are emitted and move around the globe by any mode or means, could inform policies aiming to prevent harmful effects on environmental and human health in areas "remote" from initial source regions, irrespective of whether remote regions refer to polar, tropical or other regions. The example for PCBs highlights significant time-lags between initial control measures through bans on production (Figure 3A) and exports (Figure 3B), followed by primary emissions from informal recycling in developing regions. Without a more holistic understanding of emissions across chemical life-cycles, time and space, important cobenefits for integrated chemical management strategies of IUOCs may be overlooked. Our findings highlight that exports of e-waste containing IUOCs toward tropical areas are likely to increase global emissions and thereby exposures. Further efforts to reduce emissions of IUOCs from informal e-waste recycling in developing regions may therefore not only be beneficial to minimize harmful effects on environmental and human health in such communities, but also potentially have a positive impact on a regional and even global scale, including exporting regions.

\section{ASSOCIATED CONTENT}

\section{S Supporting Information}

The Supporting Information is available free of charge on the ACS Publications website at DOI: 10.1021/acs.est.5b04226.

Additional information, Tables S1-S3, and Figures S1S4 (PDF) 


\section{AUTHOR INFORMATION}

\section{Corresponding Authors}

*(K.B.) Phone: +47 63898000; fax: +47 63898050; e-mail: kbr@nilu.no.

*(J.M.A.) Phone: +1 4162877277 ; fax: +1 416287 7279; email: james.armitage@utoronto.ca.

\section{Notes}

The authors declare no competing financial interest.

\section{ACKNOWLEDGMENTS}

This study was financed by the Research Council of Norway (213577). We thank Sabine Eckhardt for preparing Figure S3. The global PCB emission scenarios from this study are available at www.nilu.no/projects/globalpcb/.

\section{REFERENCES}

(1) Wania, F.; Mackay, D. Global fractionation and cold condensation of low volatility organochlorine compounds in polar regions. Ambio 1993, 22 (1), 10-18.

(2) Vallack, H. W.; Bakker, D. J.; Brandt, I.; Broström-Lundén, E.; Brouwer, A.; Bull, K. R.; Gough, C.; Guardans, R.; Holoubek, I.; Jansson, B.; Koch, R.; Kuylenstierna, J.; Lecloux, A.; Mackay, D.; McCutcheon, P.; Mocarelli, P.; Taalman, R. D. F. Controlling Persistent Organic Pollutants - what next? Environ. Toxicol. Pharmacol. 1998, 6 (3), 143-175.

(3) Hung, H.; Kallenborn, R.; Breivik, K.; Su, Y. S.; BroströmLundén, E.; Olafsdottir, K.; Thorlacius, J. M.; Leppanen, S.; Bossi, R.; Skov, H.; Manø, S.; Patton, G. W.; Stern, G.; Sverko, E.; Fellin, P. Atmospheric monitoring of organic pollutants in the Arctic under the Arctic Monitoring and Assessment Programme (AMAP): 1993-2006. Sci. Total Environ. 2010, 408 (15), 2854-2873.

(4) AMAP. Trends in Stockholm Convention Persistent Organic Pollutants (POPs) in Arctic Air, Human media and Biota. Arctic Monitoring and Assessment Programme, Technical Report No.7, 2014; ISBN 978-82-7971-084-4.

(5) Scheringer, M. Persistence and spatial range as endpoints of an exposure-based assessment of organic chemicals. Environ. Sci. Technol. 1996, 30 (5), 1652-1659.

(6) Wania, F. Potential of degradable organic chemicals for absolute and relative enrichment in the Arctic. Environ. Sci. Technol. 2006, 40 (2), 569-577.

(7) Eckhardt, S.; Breivik, K.; Manø, S.; Stohl, A. Record high peaks in PCB concentrations in the Arctic atmosphere due to long-range transport of biomass burning emissions. Atmos. Chem. Phys. 2007, 7 (17), 4527-4536.

(8) Lammel, G.; Stemmler, I. Fractionation and current time trends of PCB congeners: evolvement of distributions 1950-2010 studied using a global atmosphere-ocean general circulation model. Atmos. Chem. Phys. 2012, 12 (15), 7199-7213.

(9) UNEP Gloval Monitoring Plan. http://chm.pops.int/ Implementation/GlobalMonitoringPlan/Overview/tabid/83/Default. aspx.

(10) Wania, F.; Mackay, D. Tracking the distribution of Persistent Organic Pollutants. Environ. Sci. Technol. 1996, 30 (9), A390-A396.

(11) UNEP/AMAP. Climate change and POPs: Predicting the impacts. Report of the UNEP/AMAP Expert Group, 2011.

(12) Lamon, L.; von Waldow, H.; MacLeod, M.; Scheringer, M.; Marcomini, A.; Hungerbuhler, K. Modeling the global levels and distribution of polychlorinated biphenyls in air under a climate change scenario. Environ. Sci. Technol. 2009, 43 (15), 5818-5824.

(13) Armitage, J.; Cousins, I. T.; Buck, R. C.; Prevedouros, K.; Russell, M. H.; MacLeod, M.; Korzeniowski, S. H. Modeling globalscale fate and transport of perfluorooctanoate emitted from direct sources. Environ. Sci. Technol. 2006, 40 (22), 6969-6975.

(14) Wong, M. H.; Wu, S. C.; Deng, W. J.; Yu, X. Z.; Luo, Q.; Leung, A. O. W.; Wong, C. S. C.; Luksemburg, W. J.; Wong, A. S. Export of toxic chemicals - A review of the case of uncontrolled electronic-waste recycling. Environ. Pollut. 2007, 149 (2), 131-140.

(15) Iles, A. Mapping environmental justice in technology flows: Computer waste impacts in Asia. Global Environmental Politics 2004, 4 (4), 76-107.

(16) Grossman, E. High Tech Trash: Digital Devices, Hidden Toxics, and Human Health; First Island Press paperback ed.: Washington DC, 2006.

(17) Rucevska, I.; Nelleman, C.; Isarin, N.; Yang, W.; Liu, N.; Yu, K.; Sandnæs, S.; Olley, K.; McCann, H.; Devia, L.; Bisschop, L.; Soesilo, D.; Schoolmeester, T.; Henriksen, R.; Nilsen, R., Waste crime - waste risks. Gaps in meeting the global waste challenge. In A UNEP Rapid Response Assessment. United Nations Environment Programme and GRID-Arendal. ISBN: 978-82-7701-148-6, 2015.

(18) Xing, G. H.; Chan, J. K. Y.; Leung, A. O. W.; Wu, S. C.; Wong, M. H. Environmental impact and human exposure to PCBs in Guiyu, an electronic waste recycling site in China. Environ. Int. 2009, 35 (1), $76-82$.

(19) Li, Y. M.; Jiang, G. B.; Wang, Y. W.; Wang, P.; Zhang, Q. H. Concentrations, profiles and gas-particle partitioning of PCDD/Fs, PCBs and PBDEs in the ambient air of an E-waste dismantling area, southeast China. Chin. Sci. Bull. 2008, 53 (4), 521-528.

(20) Han, W. L.; Feng, J. L.; Gu, Z. P.; Wu, M. H.; Sheng, G. Y.; Fu, J. M. Polychlorinated biphenyls in the atmosphere of Taizhou, a major e-waste dismantling area in China. J. Environ. Sci. 2010, 22 (4), 589597.

(21) Gioia, R.; Eckhardt, S.; Breivik, K.; Jaward, F. M.; Prieto, A.; Nizzetto, L.; Jones, K. C. Evidence for major emissions of PCBs in the West African region. Environ. Sci. Technol. 2011, 45, 1349-1355.

(22) Xie, Z.; Müller, A.; Ahrens, L.; Sturm, R.; Ebinghaus, R. Brominated flame retardants in seawater and atmosphere of the Atlantic and the Southern Ocean. Environ. Sci. Technol. 2011, 45 (5), $1820-1826$.

(23) Tsydenova, O.; Bengtsson, M. Chemical hazards associated with treatment of waste electrical and electronic equipment. Waste Manage. 2011, 31 (1), 45-58.

(24) Chen, S.-J.; Tian, M.; Wang, J.; Shi, T.; Luo, Y.; Luo, X.-J.; Mai, B.-X. Dechlorane Plus (DP) in air and plants at an electronic waste (ewaste) site in South China. Environ. Pollut. 2011, 159 (5), 1290-1296.

(25) Tian, M.; Chen, S.-J.; Wang, J.; Zheng, X.; Luo, X.-J.; Mai, B.-X. Brominated flame retardants in the atmosphere of e-waste and rural sites in southern China: Seasonal variation, temperature dependence, and air-particle partitioning. Environ. Sci. Technol. 2011, 45, 88198825 .

(26) Chen, S.-J.; Tian, M.; Zheng, J.; Zhu, Z.-C.; Luo, Y.; Luo, X.-J.; Mai, B.-X. Elevated levels of polychlorinated biphenyls in plants, air, and soils at an e-waste site in southern China and enantioselective biotransformation of chiral PCBs in plants. Environ. Sci. Technol. 2014, 48 (7), 3847-3855.

(27) Breivik, K.; Gioia, R.; Chakraborty, P.; Zhang, G.; Jones, K. C. Are reductions in industrial organic contaminants emissions in rich countries achieved partly by export of toxic wastes? Environ. Sci. Technol. 2011, 45 (21), 9154-9160.

(28) Breivik, K.; Armitage, J. M.; Wania, F.; Jones, K. C. Tracking the global generation and exports of e-waste. Do existing estimates add up? Environ. Sci. Technol. 2014, 48 (15), 8735-8743.

(29) MacLeod, M.; von Waldow, H.; Tay, P.; Armitage, J. M.; Wöhrnschimmel, H.; Riley, W. J.; McKone, T. E.; Hungerbuhler, K. BETR global - A geographically-explicit global-scale multimedia contaminant fate model. Environ. Pollut. 2011, 159 (5), 1442-1445.

(30) Breivik, K.; Sweetman, A.; Pacyna, J. M.; Jones, K. C. Towards a global historical emission inventory for selected PCB congeners - A mass balance approach 3 An update. Sci. Total Environ. 2007, 377 (23), 296-307.

(31) Jaward, T. M.; Zhang, G.; Nam, J. J.; Sweetman, A. J.; Obbard, J. P.; Kobara, Y.; Jones, K. C. Passive air sampling of polychlorinated biphenyls, organochlorine compounds, and polybrominated diphenyl ethers across Asia. Environ. Sci. Technol. 2005, 39 (22), 8638-8645. 
(32) Breivik, K.; Sweetman, A.; Pacyna, J. M.; Jones, K. C. Towards a global historical emission inventory for selected PCB congeners - a mass balance approach 1 Global production and consumption. Sci. Total Environ. 2002, 290 (1-3), 181-198.

(33) Breivik, K.; Sweetman, A.; Pacyna, J. M.; Jones, K. C. Towards a global historical emission inventory for selected PCB congeners - a mass balance approach 2 Emissions. Sci. Total Environ. 2002, 290 (13), 199-224.

(34) Breivik, K.; Czub, G.; McLachlan, M. S.; Wania, F. Towards an understanding of the link between environmental emissions and human body burdens of PCBs using CoZMoMAN. Environ. Int. 2010, $36,86-92$.

(35) Weber, R.; Watson, A.; Forter, M.; Oliaei, F. Persistent organic pollutants and landfills - a review of past experiences and future challenges. Waste Manage. Res. 2011, 29 (1), 107-121.

(36) Macleod, M.; Riley, W. J.; McKone, T. E. Assessing the influence of climate variability on atmospheric concentrations of polychlorinated biphenyls using a global-scale mass balance model (BETR-global). Environ. Sci. Technol. 2005, 39 (17), 6749-6756.

(37) Wöhrnschimmel, H.; MacLeod, M.; Hungerbuhler, K. Global multimedia source-receptor relationships for Persistent Organic Pollutants during use and after phase-out. Atmos. Pollut. Res. 2012, 3 (4), 392-398.

(38) Anderson, P. N.; Hites, R. A. OH radical reactions: The major removal pathway for polychlorinated biphenyls from the atmosphere. Environ. Sci. Technol. 1996, 30 (5), 1756-1763.

(39) Wania, F.; Daly, G. L. Estimating the contribution of degradation in air and deposition to the deep sea to the global loss of PCBs. Atmos. Environ. 2002, 36 (36-37), 5581-5593.

(40) Schenker, U.; MacLeod, M.; Scheringer, M.; Hungerbuhler, K. Improving data quality for environmental fate models: A least-squares adjustment procedure for harmonizing physicochemical properties of organic compounds. Environ. Sci. Technol. 2005, 39 (21), 8434-8441.

(41) Mackay, D. Multimedia Environmental Models: The Fugacity Approach, 2nd ed.; CRC Press: Boca Raton, FL, 2001.

(42) Armitage, J. M.; Quinn, C. L.; Wania, F. Global climate change and contaminants-an overview of opportunities and priorities for modelling the potential implications for long-term human exposure to organic compounds in the Arctic. J. Environ. Monit. 2011, 13 (6), $1532-46$.

(43) Yang, H. Y.; Zhuo, S. S.; Xue, B.; Zhang, C. L.; Liu, W. P. Distribution, historical trends and inventories of polychlorinated biphenyls in sediments from Yangtze River Estuary and adjacent East China Sea. Environ. Pollut. 2012, 169, 20-26.

(44) Asante, K. A.; Adu-Kumi, S.; Nakahiro, K.; Takahashi, S.; Isobe, T.; Sudaryanto, A.; Devanathan, G.; Clarke, E.; Ansa-Asare, O. D.; Dapaah-Siakwan, S.; Tanabe, S. Human exposure to PCBs, PBDEs and HBCDs in Ghana: Temporal variation, sources of exposure and estimation of daily intakes by infants. Environ. Int. 2011, 37 (5), 921928. 